\title{
SIMULATING CRACK PROPAGATION OF A SELECTED STRUCTURAL COMPONENT OF THE PZL-130 ORLIK TC-II AIRCRAFTS
}

\author{
Krzysztof Jankowski \\ Piotr Reymer \\ Air Force Institute of Technology, ul. Ks. Bolestawa 6, 01-494 Warsaw, Poland \\ krzysztof.jankowski@itwl.pl, piotr.reymer@itwl.pl
}

\begin{abstract}
This paper presents the process of estimating crack propagation within a selected structural component of the PZL-130 Orlik TC-II using a numerical model. The model is based on technical drawings and measurements of the real structure. The proper definition of the geometry, including the location and size of the gap between elements, is significant for mesh generation. During the simulation process the gap is combined node by node. Each time, the strain energy release rate $(G)$ is calculated. The stress intensity factor and geometry correction factor are defined for consecutive crack lengths, and used further on to estimate crack propagation.
\end{abstract}

Keywords: structural integrity, crack propagation simulation, geometry correction factor

\section{INTRODUCTION}

The PZL-130 Orlik TC-II is a preliminary military training aircraft used in the Polish Armed Forces. The Air Force Institute of Technology (AFIT) is participates in a programme aimed at the service life assessment of this aircraft? (SEWST). The main goal of the programme is to enable operation according to the damage tolerance approach, which will allow omitting the necessity of time consuming overhauls. The SEWST is divided into a number of diverse tasks concerned not only with the structure but also with the avionics and related systems. The most significant tasks related to the aircraft's structure are: Operational Load Monitoring programme, Full Scale Fatigue Test (FSFT) of the aircraft's structure, laboratory material testing and numerical crack propagation calculations.

The damage tolerance approach assumes that when a flaw is present in a structure the operational loads being exerted on the structure may cause the crack to propagate leading to the structure's failure. Crack propagation will occur when the stress intensity factor (K) for the particular load cycle is higher than Kth (a threshold value at which a fracture does not propagate) and lower than $\mathrm{K}_{\mathrm{IC}}$ (fracture toughness) [1]. Moreover, when the stress condition is such that the $\mathrm{K}_{\mathrm{IC}}$ value is exceeded, the specimen will fail critically due to brittle fracture. Therefore, $\mathrm{K}_{\mathrm{IC}}$ has a similar meaning in fracture mechanics as yield strength in the strength material approach.

Aeronautical structures exposed to varying operational loads tend to develop fatigue damages. Damages in the primary structure, which is responsible for transferring operational loads, significantly compromise the integrity of the structure. Hence, the regions where such damages occur are designated as Critical Points (Cps). However, the location of these points and the rate of damage growth is not easy to define. A method which is the most effective and safest with respect to defining damage location is a Full Scale Fatigue Test. 


\section{PROBLEM DESCRIPTION}

This article focuses on a single CP, wings lower spar overlay near rib 0 (Fig. 1), where fatigue damage was discovered during Non-Destructive Investigation (NDI). A crack initiated from the edge of the lower flange and propagated until it reached the upper end of the element.

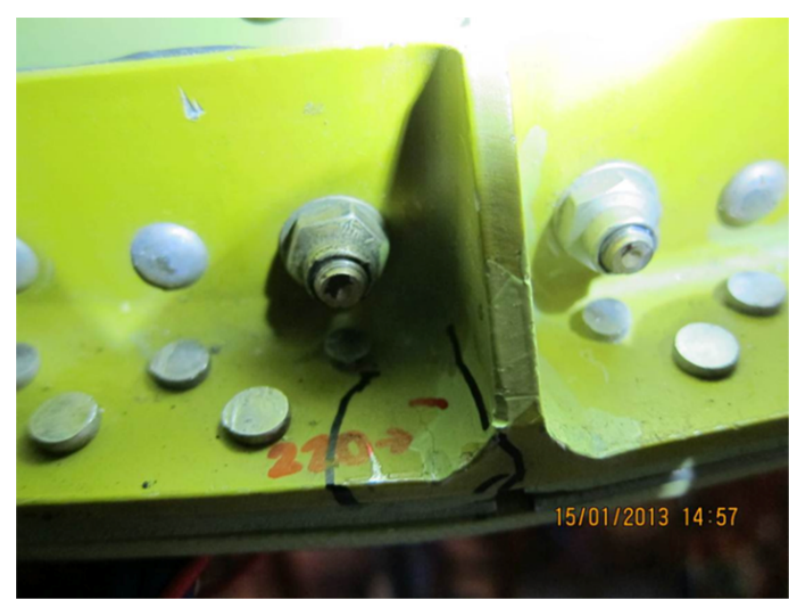

Fig. 1. Critical point

The aim of the analysis was to carry out numerical calculations which would allow engineers to determine crack propagation curves. The obtained curves would allow defining a safe region where a crack propagates at a relatively slow speed and defining inspection intervals based on the detectable crack size. The analysis involved four steps:(i) the preparation with the finite element method of a model of the damaged element as well as the adjacent structure influencing load distribution in the $\mathrm{CP}$ in order to determine the geometry correction factor ( $\beta$ ) [2]; (ii) definition of a load spectrum based on strain gauge measurements;(iii) laboratory tests to determine material properties; (iv) and crack propagation calculations.

\section{FINITE ELEMENT MODEL}

\section{Preparation of the model}

The finite element model was based on the geometrical model of the whole wing's structure (Fig. 2). A red circle indicates the critical point area of the element. Elements significant for the analysis were defined and prepared to mesh by proper cutting of solids (Fig. 3). As the model is symmetrical Fig. 3 shows only a half of the model.

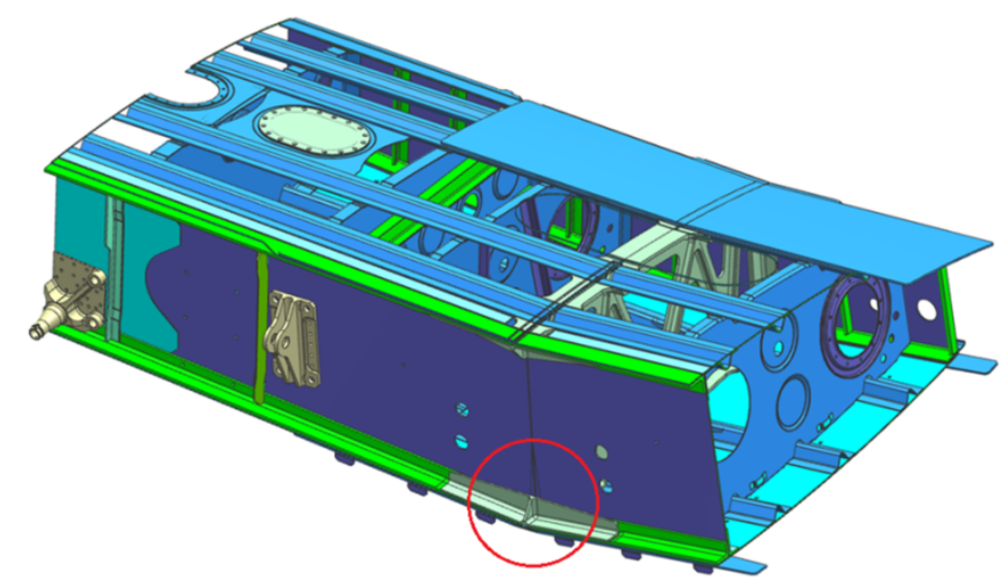

Fig. 2. Wing's structure with a crack area indicated by a red circle 


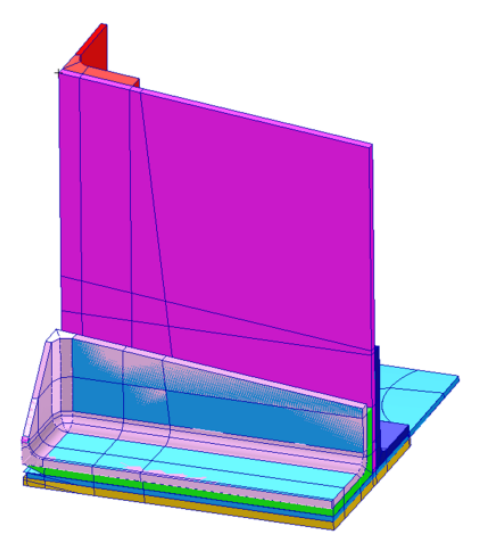

Fig. 3. Half of the proper geometry

The numerical model was prepared in the Msc.Patran software using solid elements. The total number of elements in the model was 93,054. Separate structural elements (shown in Fig. 4 and 5 with different colors) were connected by joining adequate nodes, which permitted a simplified simulation of the riveted joints (without contact problems). The holes for screws and rivets were neglected.

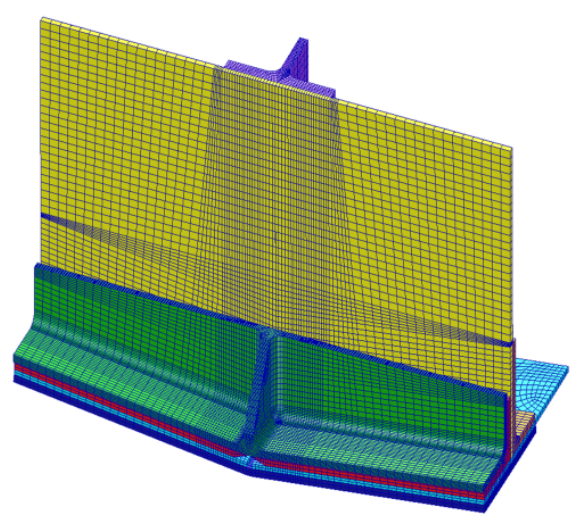

Fig. 4. Numerical model viewed from the rear of the aircraft

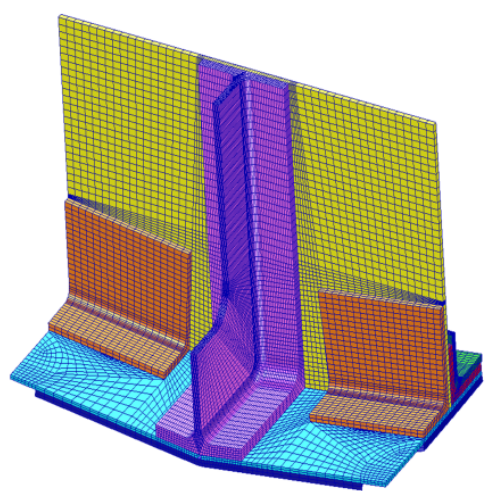

Fig. 5. Numerical model viewed from the front of the aircraft

\section{Boundary conditions}

Boundary conditions were applied by means of a displacement field obtained from a global model of the aircraft (Fig. 6). To achieve good quality of the displacement field, the mesh around 
the critical point area was concentrated. The global model of the aircraft was loaded similarly as during the full scale fatigue test during level flight with $\mathrm{Nz}=1$ (Fig. 7).

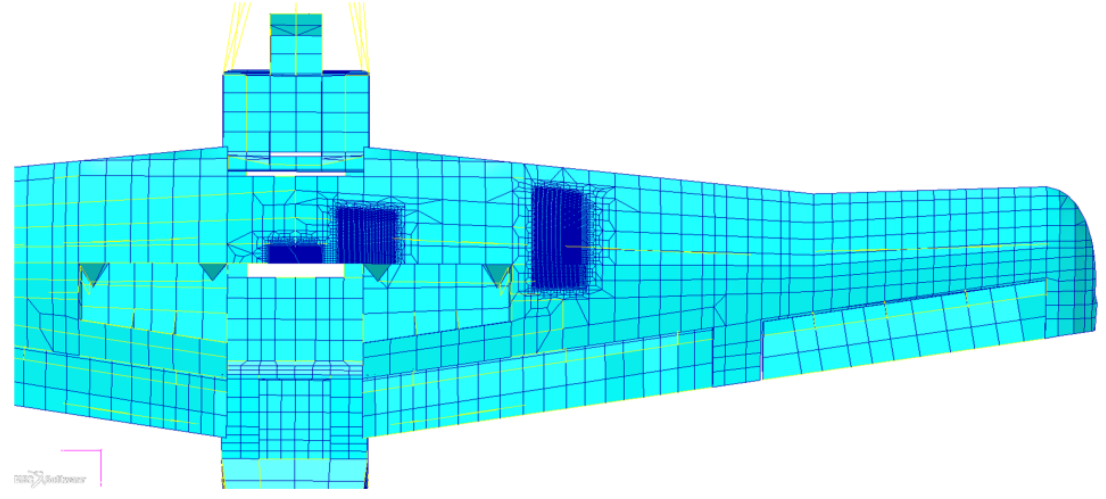

Fig. 6. Mesh of the global model

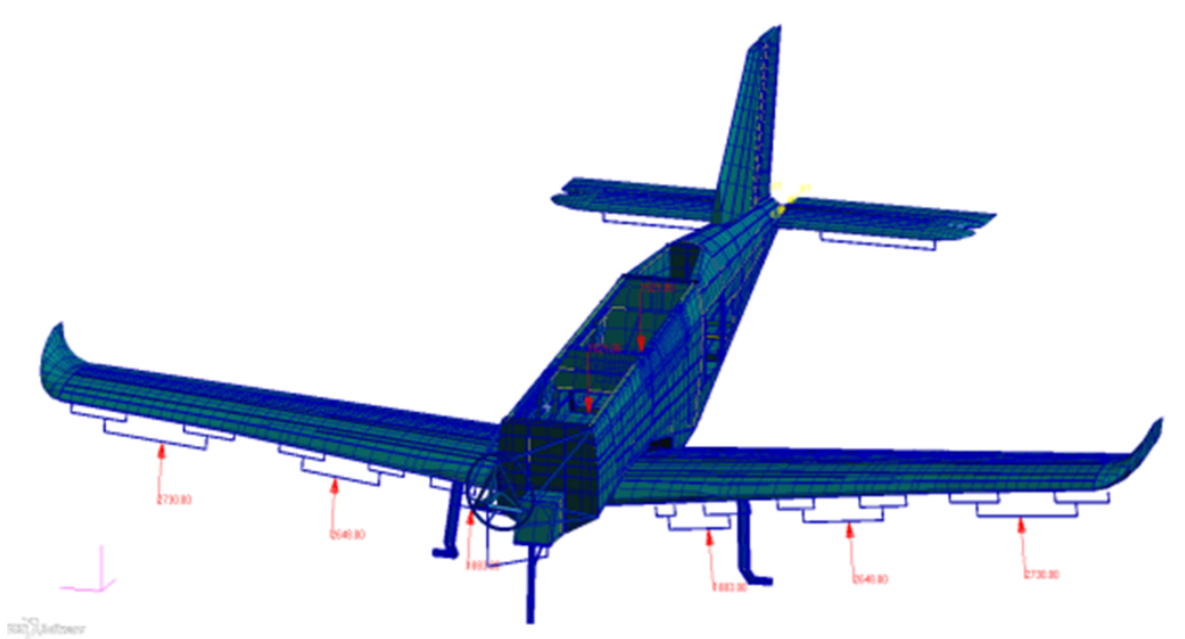

Fig. 7. Boundary conditions of the global model

Since the global model was made of shell elements in order to properly transfer the boundary conditions from the global model to the local model, additional shell elements were added to the trimmed edges of the local model (Fig. 8). All the displacement components were transferred from the global field to the local field (Fig. 9).

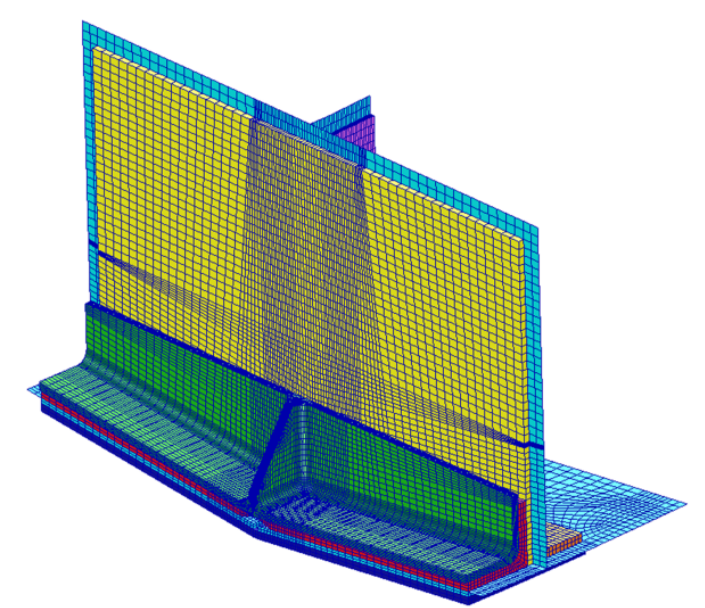

Fig. 8. Local model with shell elements 


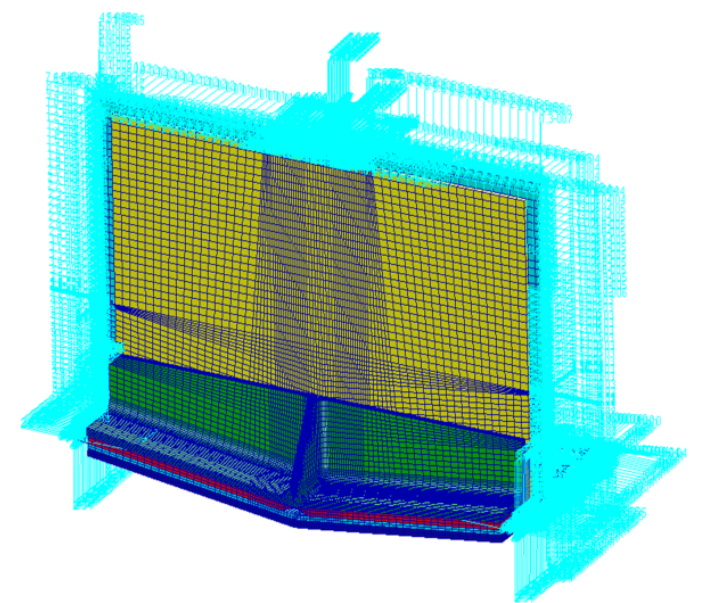

Fig. 9. Local model with the displacement field

The crack path was defined based on the NDI findings during the full scale fatigue test. It was assumed that the crack initiated from the edge of the lower flange and propagated to the web flange's upper edge as it is shown in Fig. 10.

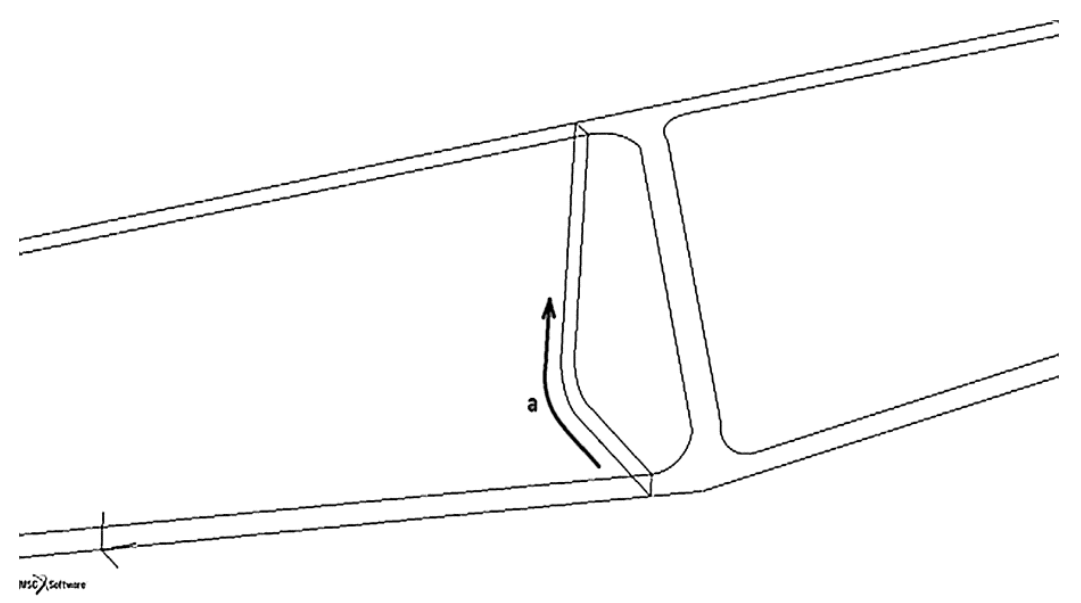

Fig. 10. Direction of the crack propagation

\section{Virtual Crack Closure Technique}

Crack propagation calculations presented in this article are based on the Virtual Crack Closure Technique (VCCT), which is an energetic method based on the assumption that energy released from a cracking material $(\mathrm{G})$ during an infinitesimally small increment is equal to the work necessary to rejoin the crack on that increment counteracting reaction forces in the nodes just in front of the crack [3-12]. Therefore in order to determine the energy release rate it is necessary to determine reaction forces in the nodes at the tip of the crack as well as displacement of nodes preceding the crack tip (Fig. 11). An additional assumption used in VCCT is that the reaction force in the neighboring nodes along the crack path is equal due to the small size of the element, therefore $\mathrm{G}$ can be estimated for each numerical step using displacement and reaction forces shown in Fig. 11. 


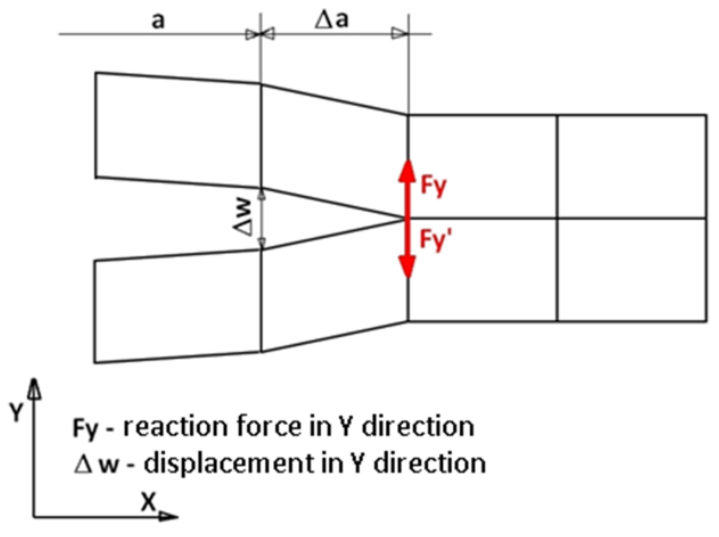

Fig. 11. VCCT description

A VCCT module in the MSC.Patran allows for simple $\mathrm{G}$ estimation by defining VCCT as load in the crack tip nodes [13]. Therefore it is sufficient to model the structure with the crack and define VCCT at the crack tip. For the defined material properties and given boundary conditions, the value of $\mathrm{G}$ is defined (total value as well as 3 separate values for each of the three crack modes: opening, in-plane shear and out-of-plane shear). Boundary conditions for the local model were determined using a global-local approach from the global numerical model of the aircraft for the level flight load case. The ratio between the three latter values of $\mathrm{G}$ indicates which mode of cracking is determined for the defined case. The value of $G$ is determined using the following formula:

$$
\mathrm{G}=\text { Fiwi2hc }
$$

where $\mathrm{Fi}$ is the reaction force, wi is the displacement whereas $\mathrm{h}$ and $\mathrm{c}$ are the lengths of the finite element.

For the crack propagation calculations, it was necessary to determine the geometry correction factor $(\beta)$, which is a dimensionless unit defining the crack intensity due to the adjacent geometry of the damaged element, and which does not depend on the stress state around the damage. In order to determine $\beta$ from the obtained value of $G$ it is necessary to carry out a series of transformations:

$$
\mathrm{K}=\mathrm{GE} \propto
$$

where $\mathrm{K}$ is the stress intensity factor, $\mathrm{E}$ is the materials Young modulus, and for plane state stress:

$$
\propto=1
$$

whereas for the plane's state strain:

$$
\propto=1-\vartheta 2
$$

where $v$ is the material's Poisson's ratio. $\beta$ is then obtained from the following formula:

$$
\beta=\text { К } \sigma \pi \mathrm{a}
$$

where $\sigma$ is the stress measured in the remote region of the element (not influenced by the stress concentrations due to the presence of the crack in the element), a is the crack length (in case a crack propagates in two directions simultaneously, the value of a is defined as the half length of the whole crack).

The values of $\beta$ obtained by the above procedure had to be tabularized against the crack length $a$ and in that form could be used in the AFGROW crack propagation program [14]. 


\section{Obtained results}

The values of $\beta$ for the nodes along the crack path were defined using the VCCT procedure described above. The obtained $\beta$ values for crack sections a and b are shown in Fig. 12.

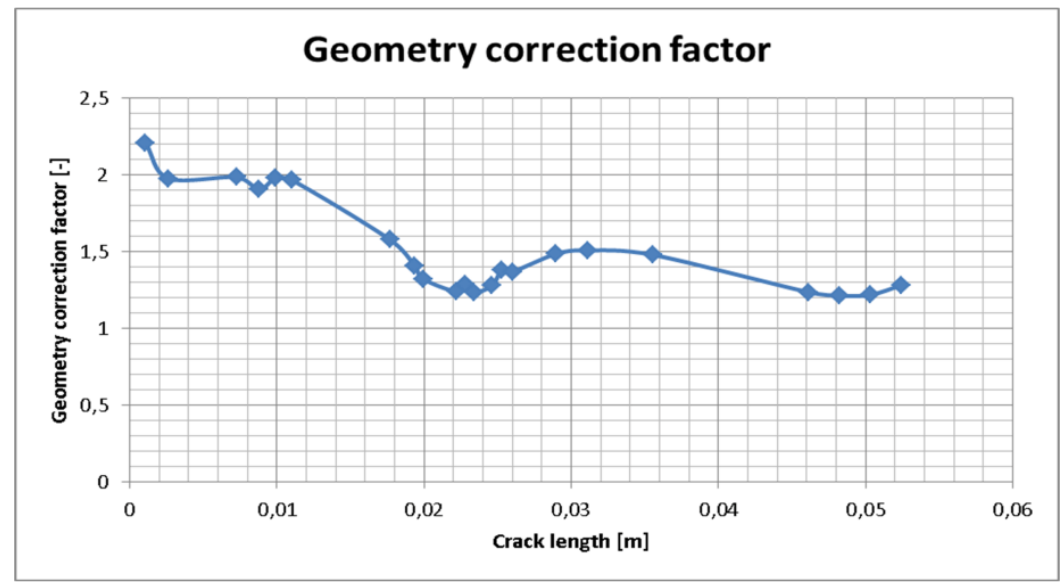

Fig. 12. Estimated $\beta$ values for section a

\section{CRACK PROPAGATION CALCULATIONS}

\section{Load spectrum}

One of the most important factors in crack propagation estimations is the load spectrum. For the purpose of the presented analysis, the load spectrum was developed based on strain measurements carried out during the FSFT of the aircraft's structure. A special strain gauge was installed on the fuselage side top near the crack site in order to measure strain in the examined element. The spectrum was prepared by converting the measured strain to stress in MPa. The prepared spectrum shown in Fig. 13 represents 800 SFH.

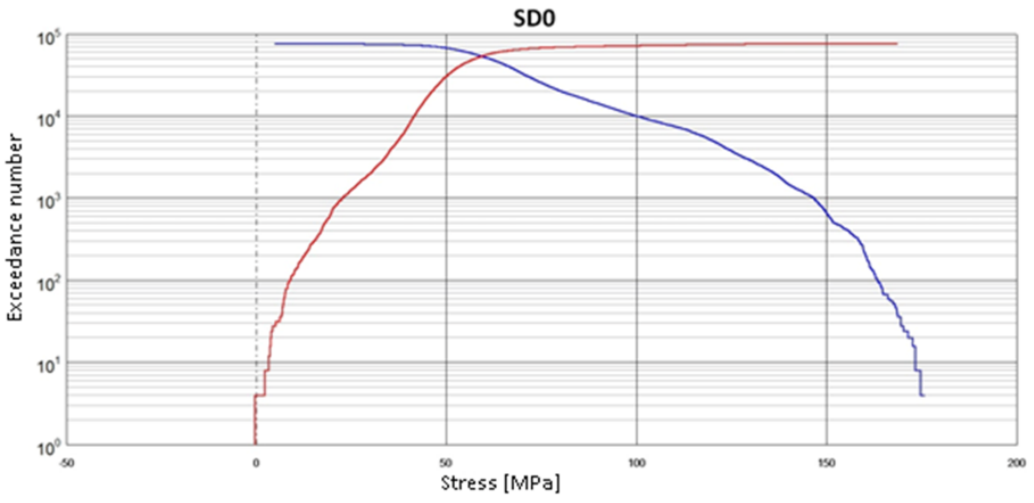

Fig. 13. Load spectrum used in calculations

\section{Material properties}

Material properties defined in the crack propagation model were taken from the material base of the AFGROW program for 2024-T351 aluminum. Additionally, the results of material tests carried out by the Laboratory for Material Strength Testing at the AFIT were used in order to prepare valid material data. The tests carried out in the laboratory were designed to determine Young's modulus as well as KIC of the material used for the aircraft's structure. Tests were conducted on 
specimens prepared according to the adequate standards (PN-EN ISO 12737:2011 and PN-EN ISO 6892-1:2010) by the aircraft's manufacturer, Airbus Military, PZL-Okęcie.

\section{Crack propagation calculations}

The calculations were carried out in the AFGROW software using the Nasgrow equation [3] Since $\beta$ values were defined for complex model, therefore included information about stress state change along crack length due to adjacent structure, a simple through crack model could be used. The model data used in calculations are presented in Table 1.

Table 1. Data used in crack propagation calculations

\begin{tabular}{|l|l|l|}
\hline Parameter & Value & Units \\
\hline Length & 0,0545 & {$[\mathrm{~m}]$} \\
\hline Thickness & 0,003 & {$[\mathrm{~m}]$} \\
\hline Initial a & 0,00109 & {$[\mathrm{~m}]$} \\
\hline $\mathrm{K}_{\mathrm{IC}}$ & 36,75 & {$[\mathrm{MPa} \sqrt{\mathrm{m}}]$} \\
\hline $\mathrm{E}$ & 72000 & {$[\mathrm{MPa}]$} \\
\hline
\end{tabular}

\section{Crack propagation curves}

The crack propagation calculations were performed using all the prepared data as described in the previous chapters. The calculations were carried out until the KIC value for the element was reached (Table 1), which means that the element cracked rapidly causing the examined structure to fail. The estimated crack propagation curve is presented in Fig. 14.

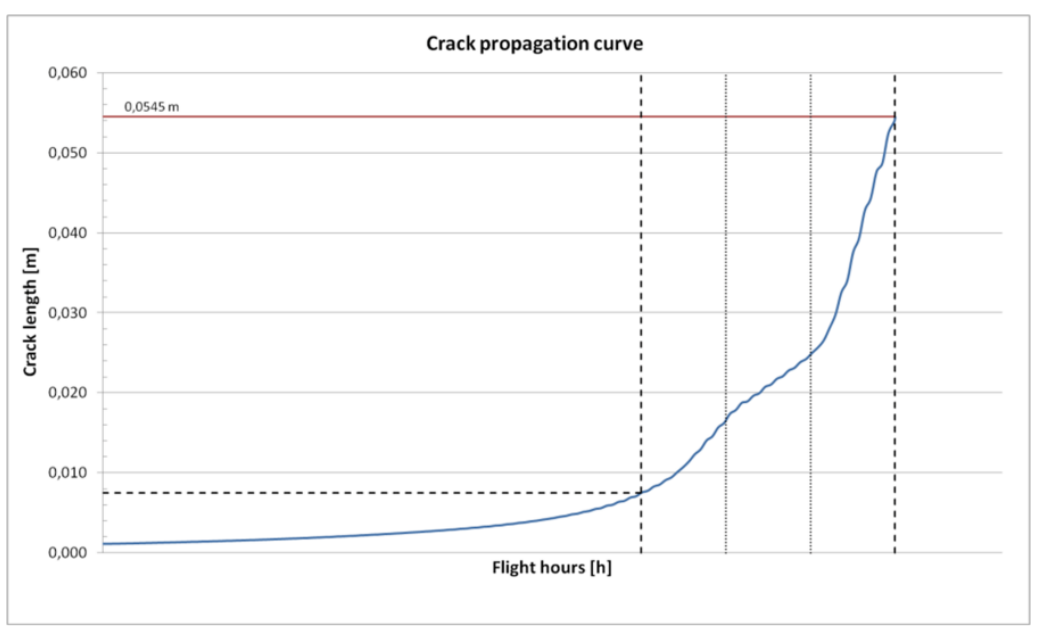

Fig. 14. Crack propagation curve

The estimated durability of the structure is consistent with the time at which the damage was discovered during NDI tests. The crack propagation curve (Fig. 14) starts in a slow and predictable manner until the crack length $0.01 \mathrm{~m}$ is reached when the crack propagation speed increases rapidly. A short time interval between the detectable crack size and critical crack size necessitates short intervals between NDI inspections. 


\section{SUMMARY}

The presented method allowed crack propagation curves to be determined corresponding to the NDI findings during the FSFT. In terms of flight hours, the obtained curves depend on the geometry of the $\mathrm{CP}$ under consideration as well as on the real load spectrum and material properties. This would allow to schedule necessary inspections (in order to determine the actual crack length as well as to verify the obtained curve) and undertake mitigating actions before cracks reach the critical value.

\section{REFERENCES}

1. T. L. Anderson, Fracture Mechanics Fundamentals and Applications, Taylor\&Francis Group, Third edition, (2005).

2. Y. Murakami, Stress Intensity Factors Handbook, Volume 1, Pergamon Press, Great Britain, 1987.

3. L. Bank-Sills, Applied Mechanics Reviews, Vol. 44, pp. 447-461, 1991.

4. I. L. Lim, I.W. Johnston, S. K. Choi, International Journal of Fracture, Vol. 58, pp. 193-210, 1992.

5. S. N. Atluri, T. Nishioka, Com-putational Methods in the Mechanics of Fracture, Elseviere, 1986, pp. 229-287, 1986.

6. K.N. Shivakumar, I.S. Raju, Engineering Fracture Mechanics, Vol. 42, No. 6, pp. 935-959, 1992.

7. E.F. Rybicki, M. F. Kanninen, Engineering Fracture Mechanics, Vol. 9, pp. 931-938, 1977.

8. K.N. Shivakumar, P.W. Tan, J.C. Newman, International Journal of Fracture, Vol. 36, pp. 4350, 1988.

9. I. S. Raju, Engineering Fracture Mechanics, Vol. 28, No. 3 pp. 251-274, 1987.

10. Leski A., Beres, W. NRC Research Council, Institute for Aerospace Research, Structures and Materials Laboratory Report, No. LTR-SMPL-2003-0158. Ottawa, 2003.

11. A. Leski, Implementacja metody 3D VCCT obliczania współczynnika intensywności naprężenia w środowisku MSC.Patran. VIII Konferencji Naukowo-Technicznej Programy MES w komputerowym wspomaganiu analizy, projektowania i wytwarzania. Warszawa Rynia 15-18.10 2003r. CD-ROM z materiałami konferencyjnymi.

12. A. Leski, Finite Elements in Analysis and Design 43, (2007), 261-268.

13. MSC.Marc user manual.

14. James A. Harter, Afgrow users guide and technical manual, Air Force Research Laboratory (1999). 